\title{
Theoretical study on effect of confinement on flexural ductility of normal and high-strength concrete beams
}

\author{
A. K. H. Kwan, * F. T. K. Au* and S. L. Chau* \\ The University of Hong Kong
}

Compared with normal concrete, high-strength concrete has higher strength but is generally more brittle. Its use in a reinforced concrete structure, if not properly controlled, could lead to an unsustainable reduction in ductility. However, confinement could be provided to improve the ductility of the structure. In this study, the effects of concrete strength and confinement on the flexural ductility of reinforced concrete beams have been evaluated by means of complete moment-curvature analysis of beam sections cast in different concretes and provided with different confinements. The results reveal that the use of high-strength concrete at a constant tension steel ratio would increase the flexural ductility, but at a constant tension to balanced steel ratio would decrease the flexural ductility. In contrast, the provision of confinement would always increase the flexural ductility. It does this in two ways: first, it increases the balanced steel ratio so that, at the same tension steel ratio, the tension to balanced steel ratio is decreased; and second, it increases the residual strength and ductility of the concrete so that, at the same tension to balanced steel ratio, the flexural ductility of the beam section is increased.

\section{Notation}

$A_{\text {cc }} \quad$ area of concrete bounded by transverse reinforcement

$A_{\mathrm{e}} \quad$ effectively confined concrete area

$A_{\text {st }} \quad$ area of tension steel reinforcement

$A_{\text {s } x} \quad$ total area of transverse reinforcement in $x$ direction

$A_{\text {s } y} \quad$ total area of transverse reinforcement in $y$ direction

$b \quad$ breadth of beam section

$b_{\mathrm{c}} \quad$ breadth of concrete core

$d \quad$ effective depth of beam section

$d_{\text {c }} \quad$ depth of concrete core

$d_{\mathrm{n}} \quad$ neutral axis depth

$E_{\mathrm{c}} \quad$ Young's modulus of concrete

$E_{\mathrm{s}} \quad$ Young's modulus of steel reinforcement

$f_{\mathrm{c}} \quad$ in-situ uniaxial compressive strength of concrete

$f_{\mathrm{i}} \quad$ stress at inflection point on descending branch of stress-strain curve

* Department of Civil Engineering, The University of Hong Kong, Hong Kong.

(MCR 1200) Paper received 11 November 2003; accepted 11 February 2004

$\begin{array}{ll}f_{\mathrm{j}} & \text { stress when } \varepsilon_{\mathrm{c}}=\varepsilon_{\mathrm{i}} \\ f_{0} & \text { peak stress on stress-strain curve of concrete } \\ f_{\mathrm{p}} & \text { lateral confining pressure provided by } \\ & \text { transverse reinforcement } \\ f_{\mathrm{r}} & \quad \text { confining stress } \\ f_{\mathrm{yh}} & \text { yield strength of transverse steel reinforcement } \\ f_{\mathrm{yt}} & \text { yield strength of longitudinal steel } \\ & \text { reinforcement } \\ h & \text { total depth of beam section } \\ M_{\mathrm{p}} & \text { peak resisting moment of beam section } \\ s & \text { spacing of transverse reinforcement } \\ \varepsilon_{\mathrm{c}} & \text { strain in concrete } \\ \varepsilon_{\mathrm{i}} & \text { strain at inflection point on descending branch } \\ & \text { of stress-strain curve } \\ \varepsilon_{\mathrm{j}} & =\varepsilon_{\mathrm{i}}+\left(\varepsilon_{\mathrm{i}}-\varepsilon_{0}\right) \\ \varepsilon_{0} & \text { strain at peak stress on stress-strain curve of } \\ & \text { concrete } \\ \varepsilon_{\mathrm{p}} & \text { residual plastic strain in steel reinforcement } \\ \varepsilon_{\mathrm{s}} & \text { strain in steel reinforcement } \\ \mu & \text { curvature ductility factor } \\ \rho_{0} & \text { balanced steel ratio of beam section } \\ \rho_{\mathrm{t}} & \text { tension steel ratio }\left(=A_{\mathrm{st}} / b d\right) \\ \sigma_{\mathrm{c}} & \text { stress in concrete } \\ \phi_{\mathrm{u}} & \text { ultimate curvature of beam section } \\ \phi_{\mathrm{y}} & \text { yield curvature of beam section }\end{array}$




\section{Introduction}

Because of its obvious advantages of higher strength, high-strength concrete is increasingly being used, particularly for constructing tall buildings and long-span bridges. However, it is generally more brittle than normal concrete, and it is mainly this that causes the concern and hesitation of many structural engineers in its use. In fact, although high-strength concrete is by itself more brittle, as exemplified by the shorter and steeper descending branch of its stress-strain curve, ${ }^{1}$ a reinforced concrete structure cast in high-strength concrete is not necessarily more brittle than a similar one cast in normal concrete. Various structural parameters affect the ductility of a reinforced concrete structure, and the stress-strain curve of the concrete is only one of the parameters that have significant effects. For example, the details of the steel reinforcement, such as the tension and compression steel ratios and the amount of confinement provided, generally have a greater effect on the ductility of the structure than the stress-strain curve of the concrete used. If the effects of the various structural parameters on ductility are known quantitatively, the potential reduction in ductility of the structure due to the use of high-strength concrete may be more than compensated for by adjusting the reinforcement details.

There is, nevertheless, the major problem that it is difficult to predict the ductility of a reinforced concrete member: although the strength can be determined using conventional structural theories, it is not possible to evaluate the ductility using any simple method. To evaluate the ductility of a concrete member, non-linear analysis extended well into the post-peak range is needed, so that the complete load-deflection or moment-curvature curve may be obtained. Such an analysis is highly non-linear, and usually requires many iteration steps for a numerical solution. Moreover, it has been found that, at the post-peak stage, strain reversal occurs in the tension reinforcement (see below), and as a result the stress-strain relation of the tension reinforcement is stress-path dependent. Because of the complexities involved, there have been few theoretical studies on the post-peak behaviour and ductility of concrete structures. ${ }^{2-4}$

The authors' research team has recently developed a new method of analysing the post-peak flexural behaviour of reinforced concrete sections that

(a) uses the actual stress-strain curves of the concrete so that the different stress-strain characteristics of normal and high-strength concrete may be taken into account, and

(b) incorporates the stress-path dependence of the stress-strain relation of the steel reinforcement so that the effects of strain reversal may be allowed for.

Using this new method of analysis, the complete mo- ment-curvature behaviour of singly and doubly reinforced concrete beam sections, ${ }^{5}$ the ultimate concrete strain for the design of high-strength concrete beams, ${ }^{6}$ and the effects of concrete grade and steel yield strength on the flexural ductility of reinforced concrete sections ${ }^{7}$ have been studied. It has been found that, at the post-peak stage, the neutral axis depth would keep on increasing, leading to a gradual reduction of the distance between the tension reinforcement and the neutral axis and to eventually strain reversal (i.e. a decrease in strain despite a monotonic increase in curvature) in the tension reinforcement, which could have significant effects on the post-peak behaviour.

More importantly, it has also been found that, at the same tension steel ratio, a concrete section cast in highstrength concrete actually has a higher flexural ductility than a similar concrete section cast in normal concrete, despite the fact that a higher-strength concrete should have a lower ductility. However, at the same tension to balanced steel ratio, which may be taken as a measure of the degree of the section being under- or overreinforced, a concrete section cast of high-strength concrete has a lower flexural ductility. The lower the tension to balanced steel ratio is, the higher will be the flexural ductility, and vice versa. It is in fact the tension to balanced steel ratio - that is, the degree of the concrete section being under- or over-reinforced - that is the main factor determining the flexural ductility. A concrete section cast in high-strength concrete need not be more brittle, and the potential reduction in flexural ductility due to the use of high-strength concrete may be made up simply by reducing the tension to balanced steel ratio.

However, in engineering practice, sections cast in high-strength concrete also tend to be more heavily reinforced so that the full strength potential of the high-strength concrete can be exploited. Such practice, if not carefully controlled, could lead to a dangerous situation. A heavily reinforced section (i.e. one with a high tension to balanced steel ratio) cast in highstrength concrete can be very brittle and may fail quite explosively, as has been demonstrated in an experimental study by the authors' research team. ${ }^{8}$ Thus, for a section cast in high-strength concrete, it may be necessary to limit the tension to balanced steel ratio to a relatively lower value than that used with normal concrete. Another possible way to make up for the reduction in flexural ductility is to add confinement to the concrete. The resulting confining stresses would subject the concrete to a triaxial stress condition, under which it would behave in a more ductile manner. Adding confinement to improve the ductility performance is quite common in columns but not so common in beams. Studies on the effectiveness of adding confinement also concentrate more on columns ${ }^{9-11}$ than on beams.

In this study, the effects of concrete strength and confinement on the flexural ductility of reinforced con- 
crete beams are evaluated by analysing the complete moment-curvature behaviour of beam sections cast of different grades of concrete and provided with differing amounts of confining reinforcement. The theoretical method developed by the authors' research team, which uses the actual stress-strain curves of the materials and takes into account the stress-path dependence of the stress-strain relation of the steel reinforcement, is used in the analysis.

\section{Method of analysis}

For the concrete, the unified stress-strain curve model for unconfined and confined concrete developed by Attard and Setunge ${ }^{12}$ and Attard and Stewart, ${ }^{13}$ which has been shown to be applicable to a broad range of concrete strength from 20 to $130 \mathrm{MPa}$, is adopted. In this model, the main parameters used to define the stress-strain relation are: the peak stress, $f_{0}$; the strain at peak stress, $\varepsilon_{0}$; and two dimensionless coefficients $A$ and $B$, which are dependent on the concrete grade and the confining stress. The equation of the stress-strain curve is

$$
\frac{\sigma_{\mathrm{c}}}{f_{0}}=\frac{A\left(\varepsilon_{\mathrm{c}} / \varepsilon_{0}\right)+B\left(\varepsilon_{\mathrm{c}} / \varepsilon_{0}\right)^{2}}{1+(A-2)\left(\varepsilon_{\mathrm{c}} / \varepsilon_{0}\right)+(B+1)\left(\varepsilon_{\mathrm{c}} / \varepsilon_{0}\right)^{2}}
$$

in which $\sigma_{\mathrm{c}}$ and $\varepsilon_{\mathrm{c}}$ are the compressive stress and strain at any point on the stress-strain curve. Taking into account the confining effect, the peak stress $f_{0}$ and the strain $\varepsilon_{0}$ at peak stress have been derived as

$$
\begin{gathered}
f_{0}=f_{\mathrm{c}}\left(1+\frac{f_{\mathrm{r}}}{0 \cdot 56 \sqrt{f_{\mathrm{c}}}}\right)^{k} \\
\varepsilon_{0}=\left[\frac{4 \cdot 11\left(f_{\mathrm{c}}\right)^{0 \cdot 75}}{E_{\mathrm{c}}}\right]\left[1+\left(17 \cdot 0-0 \cdot 06 f_{\mathrm{c}}\right)\left(\frac{f_{\mathrm{r}}}{f_{\mathrm{c}}}\right)\right]
\end{gathered}
$$

where $f_{\mathrm{c}}$ is the peak stress under unconfined conditions, $f_{\mathrm{r}}$ is the confining stress, $E_{\mathrm{c}}$ is the initial Young's modulus, and $k$ is a factor dependent on the concrete grade (all units for stresses and modulus are in $\mathrm{MPa}$ ). Note that the peak stress, $f_{\mathrm{c}}$, is actually the in-situ uniaxial compressive strength of the concrete, which may be determined from the standard cylinder or cube strength using appropriate conversion factors. The confining stress, $f_{\mathrm{r}}$, is dependent on the transverse reinforcement, and may be evaluated using the method presented in the Appendix.

Two sets of values for $A$ and $B$, one for the ascending branch and the other for the descending branch, are used to define the shape of the stress-strain curve, as given below:

For the ascending branch:

$$
A=\frac{E_{\mathrm{c}} \varepsilon_{0}}{f_{0}}
$$

$$
B=\frac{(A-1)^{2}}{0 \cdot 55}-1
$$

For the descending branch:

$$
\begin{aligned}
& A=\left(\frac{\varepsilon_{\mathrm{j}}-\varepsilon_{\mathrm{i}}}{\varepsilon_{0}}\right)\left[\frac{\varepsilon_{\mathrm{j}} f_{\mathrm{i}}}{\varepsilon_{\mathrm{i}}\left(f_{0}-f_{\mathrm{i}}\right)}-\frac{4 \varepsilon_{\mathrm{i}} f_{\mathrm{j}}}{\varepsilon_{\mathrm{j}}\left(f_{0}-f_{\mathrm{j}}\right)}\right] \\
& B=\left(\varepsilon_{\mathrm{i}}-\varepsilon_{\mathrm{j}}\right)\left[\frac{f_{\mathrm{i}}}{\varepsilon_{\mathrm{i}}\left(f_{0}-f_{\mathrm{i}}\right)}-\frac{4 f_{\mathrm{j}}}{\varepsilon_{j}\left(f_{0}-f_{\mathrm{j}}\right)}\right]
\end{aligned}
$$

where $\varepsilon_{\mathrm{i}}$ is the strain at the inflection point on the descending branch of the stress-strain curve, $\varepsilon_{\mathrm{j}}=\varepsilon_{\mathrm{i}}+$ $\left(\varepsilon_{\mathrm{i}}-\varepsilon_{0}\right), f_{\mathrm{i}}$ is the stress when $\varepsilon_{\mathrm{c}}=\varepsilon_{\mathrm{i}}$, and $f_{\mathrm{j}}$ is the stress when $\varepsilon_{\mathrm{c}}=\varepsilon_{\mathrm{j}}$.

The values of $\varepsilon_{\mathrm{i}}, f_{\mathrm{i}}$ and $f_{\mathrm{j}}$ have been obtained by analysing available experimental data, which yields:

$$
\begin{aligned}
& \varepsilon_{\mathrm{i}}=\varepsilon_{0}\left[2+\frac{2 \cdot 5-0.3 \ln \left(f_{\mathrm{c}}\right)-2}{1+1 \cdot 12\left(f_{\mathrm{r}} / f_{\mathrm{c}}\right)^{0.26}}\right] \\
& f_{\mathrm{i}}=f_{0}\left[1+\frac{1 \cdot 41-0 \cdot 17 \ln \left(f_{\mathrm{c}}\right)-1}{1+5 \cdot 06\left(f_{\mathrm{r}} / f_{\mathrm{c}}\right)^{0.57}}\right] \\
& f_{\mathrm{j}}=f_{0}\left[1+\frac{1 \cdot 45-0.25 \ln \left(f_{\mathrm{c}}\right)-1}{1+6.35\left(f_{\mathrm{r}} / f_{\mathrm{c}}\right)^{0.62}}\right]
\end{aligned}
$$

Figure 1(a) shows some typical stress-strain curves obtained for unconfined concrete with $f_{\mathrm{c}}$ ranging from 30 to $90 \mathrm{MPa}$, and Fig. 1(b) shows some typical stress-strain

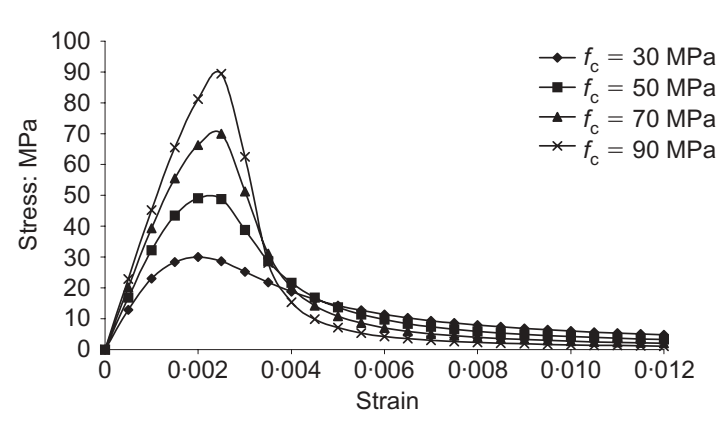

(a)

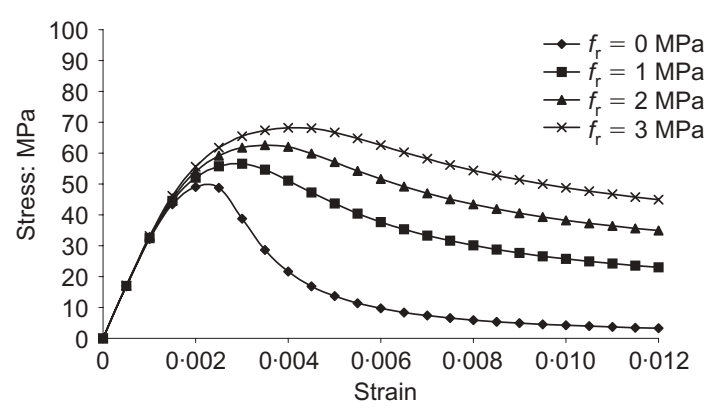

(b)

Fig. 1. Stress-strain curves of concrete: (a) unconfined concrete of various grades; (b) confined concrete with $f_{\mathrm{c}}=50 \mathrm{MPa}$ 
curves for confined concrete with $f_{\mathrm{c}}$ equal to $50 \mathrm{MPa}$ and $f_{\mathrm{r}}$ ranging from 0 to $3 \mathrm{MPa}$.

For the steel reinforcement, a linearly elasticperfectly plastic stress-strain curve is adopted. As there could be strain reversal in the steel reinforcement at the post-peak stage despite monotonic increase of curvature, the stress-strain curve of the steel is stress-path dependent. When the strain is increasing, the stressstrain relation of the steel is given by

At elastic stage:

$$
\sigma_{\mathrm{s}}=E_{\mathrm{s}} \varepsilon_{\mathrm{s}}
$$

After yielding:

$$
\sigma_{\mathrm{s}}=f_{\mathrm{yt}}
$$

where $\sigma_{\mathrm{s}}$ and $\varepsilon_{\mathrm{s}}$ are the stress and strain in the steel, $E_{\mathrm{s}}$ is the Young's modulus, and $f_{\mathrm{yt}}$ is the yield strength. In the event that strain reversal occurs after the steel has yielded, the stress in the steel will decrease instead of remaining at the yield stress level. It is assumed that the steel stress will decrease by following a straight line with the same slope as the initial Young's modulus of the steel until it reaches zero stress. Denoting the residue plastic strain in the steel by $\varepsilon_{\mathrm{p}}$, the steel stress when strain reversal occurs can be evaluated as follows:

During strain reversal:

$$
\sigma_{\mathrm{s}}=E_{\mathrm{s}}\left(\varepsilon_{\mathrm{s}}-\varepsilon_{\mathrm{p}}\right)
$$

The complete stress-strain curve of the steel reinforcement with the stress-path dependence arising from strain reversal incorporated is illustrated in Fig. 2.

The beam sections considered for analysis are shown in Fig. 3. Three basic assumptions have been made in the analysis:

(a) A plane section before bending remains plane after bending.

(b) The tensile strength of concrete is negligible.

(c) There is no bond-slip between concrete and steel.

These assumptions are widely accepted in the literature. ${ }^{14}$ The region bounded by the links is assumed to

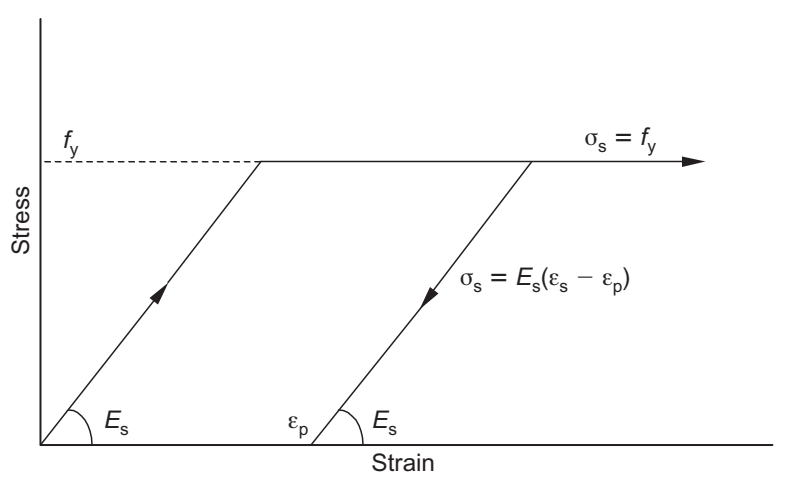

Fig. 2. Stress-strain curve of steel reinforcement

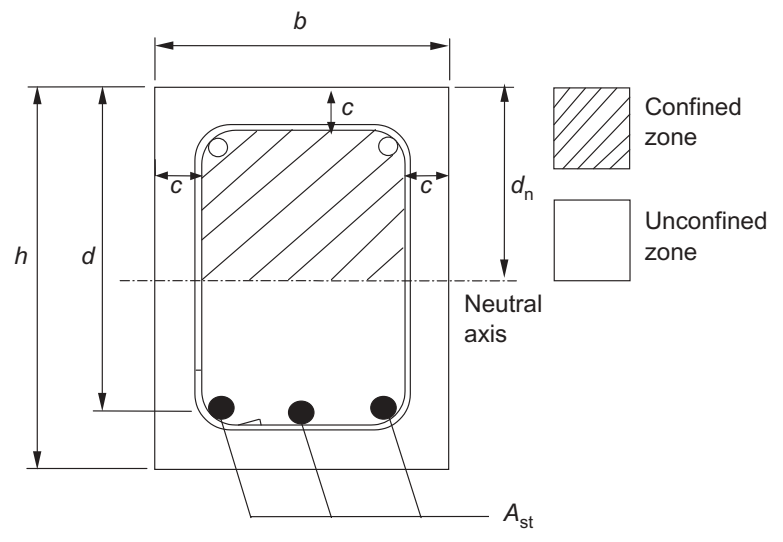

Fig. 3. Beam section analysed

be confined. For the concrete in the confined zone, confining stress is applied to evaluate the effect of confinement on the moment-curvature behaviour of the beam section, whereas for the concrete in the unconfined zone the confining stress is always taken as zero. On the other hand, for the steel reinforcement, the stress-path dependence due to strain reversal is taken into account. The moment-curvature behaviour of the beam section is analysed by applying prescribed curvatures to the beam section incrementally, starting from zero. At a prescribed curvature, the strain profile is first evaluated based on the above assumptions. From the strain profile so obtained, the stresses developed in the concrete and the steel reinforcement are determined from their respective stress-strain curves. The stresses developed have to satisfy the axial equilibrium condition, from which the neutral axis depth is evaluated by iteration. Having determined the neutral axis depth, the resisting moment is calculated from the moment equilibrium condition. The above procedure is repeated until the complete moment-curvature curve is obtained. Details of the numerical procedures have been presented previously. 5

\section{Moment-curvature behaviour}

\section{Sections analysed for parametric study}

The beam sections analysed have dimensions of $b=$ $300 \mathrm{~mm}, h=600 \mathrm{~mm}$ and $d=550 \mathrm{~mm}$. They represent typical rectangular reinforced concrete beam sections. To allow for the practical situation that not all the concrete in the compression zone can be confined, so that there always remains an unconfined zone, the value of $c$ (thickness of the unconfined zone) is varied from 0 to $60 \mathrm{~mm}$. For the parametric study, the concrete strength, $f_{\mathrm{c}}$, is varied from 30 to $90 \mathrm{MPa}$ to cover both normal and high-strength concrete; the confining stress, $f_{\mathrm{r}}$, is varied from 0 to $3 \mathrm{MPa}$ to evaluate the effect of confinement; and the tension steel ratio, $\rho_{\mathrm{t}}\left(=A_{\mathrm{st}} / b d\right)$, is varied from 0.2 to 1.2 times the balanced steel ratio

Magazine of Concrete Research, 2004, 56, No. 5 
to cover both under- and over-reinforced sections. The steel reinforcement is assumed to have constant Young's modulus and yield strength of $E_{\mathrm{s}}=200 \mathrm{GPa}$ and $f_{\mathrm{yt}}=$ $460 \mathrm{MPa}$ respectively.

\section{Complete moment-curvature curves}

Figure 4 shows some typical moment-curvature curves for under-reinforced sections with the concrete strength, $f_{\mathrm{c}}$, equal to 30 or $70 \mathrm{MPa}$ and the tension steel ratio, $\rho_{\mathrm{t}}$, equal to $0 \cdot 5$ times the balanced steel ratio of an unconfined concrete beam section. Fig. 5 shows some typical moment-curvature curves for overreinforced sections with $f_{\mathrm{c}}$ equal to 30 or $70 \mathrm{MPa}$ and $\rho_{\mathrm{t}}$ equal to 1.2 times the balanced steel ratio of an unconfined concrete beam section. (Note that the tension steel ratios of beam sections cast of the same concrete are the same, and independent of the confining stresses provided.)

From these figures, it can be seen that for underreinforced sections, regardless of whether they are cast in normal or high-strength concrete, the confining stresses applied have no effect on the momentcurvature behaviour before the beam sections reach their respective peak resisting moments. Consequently, the confining stresses applied to the beam sections, which would not cause any change to the peak moments reached, have no beneficial effect on the flexural strength of the beam sections. This is probably the reason why engineers seldom consider providing con-

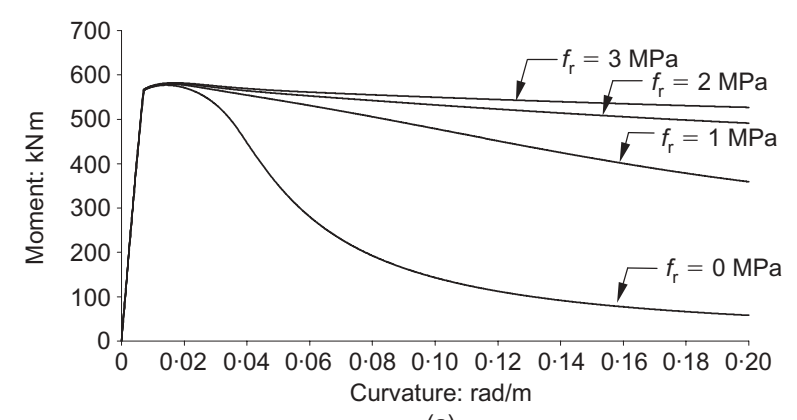

(a)

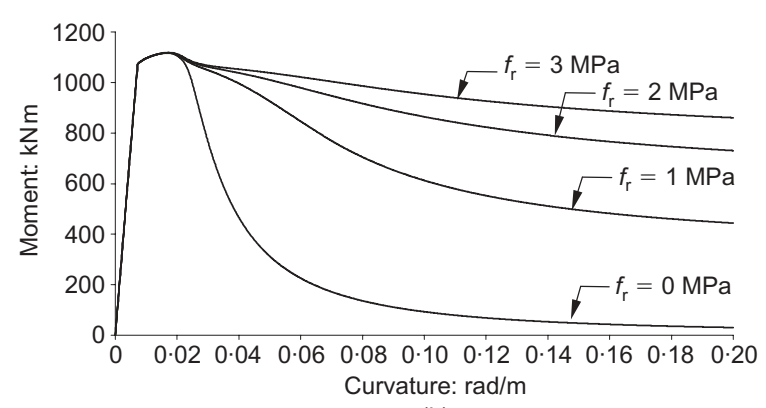

(b)

Fig. 4. Moment-curvature curves of under-reinforced sections $\left(\rho_{\mathrm{t}}=0 \cdot 5 \rho_{b\left(f_{\mathrm{r}}=0\right)}\right):$ (a) $f_{\mathrm{c}}=30 \mathrm{MPa}, c=40 \mathrm{~mm}$; (b) $f_{\mathrm{c}}=70 \mathrm{MPa}, c=40 \mathrm{~mm}$

Magazine of Concrete Research, 2004, 56, No. 5

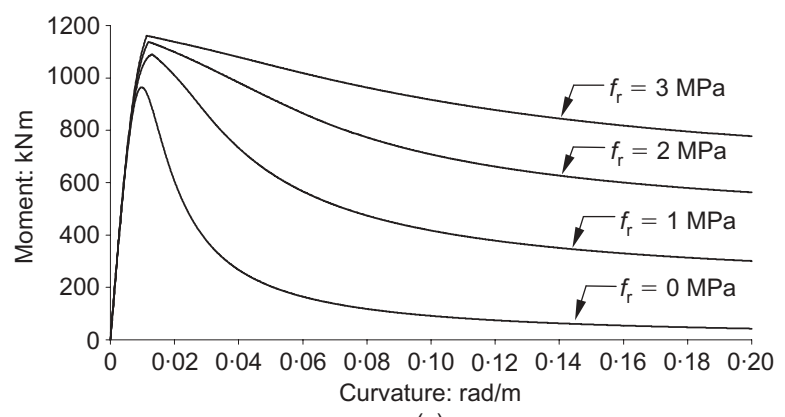

(a)

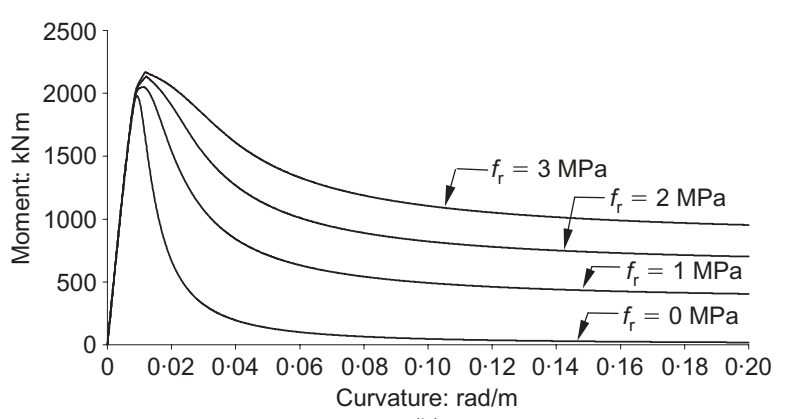

(b)

Fig. 5. Moment-curvature curves of over-reinforced sections $\left(\rho_{\mathrm{t}}=1 \cdot 2 \rho_{b\left(f_{\mathrm{r}}=0\right)}\right):\left(\right.$ a) $f_{\mathrm{c}}=30 \mathrm{MPa}, c=40 \mathrm{~mm}$; (b) $f_{\mathrm{c}}=70 \mathrm{MPa}, \mathrm{c}=40 \mathrm{~mm}$

finement to improve the flexural behaviour of reinforced concrete beams. However, it is evident from the descending branches of the moment-curvature curves that, at the post-peak stage, the confining stresses applied to the beam sections, even at just $f_{\mathrm{r}}=1 \mathrm{MPa}$, have the beneficial effect of significantly improving the flexural ductility of the beam sections.

It can also be seen that for over-reinforced sections, regardless of whether they are cast of normal or highstrength concrete, the confining stresses applied have a significant effect on the moment-curvature behaviour at both the pre-peak and post-peak stages. At the prepeak stage, the confining stresses have no effect on the flexural stiffness but would slightly increase the flexural strength of the beam sections. At the post-peak stage, the confining stresses would dramatically increase the residual moment-resisting capacities of the beam sections, thereby substantially increasing the flexural ductility of the beam sections. Hence it appears that the provision of confinement would offer greater advantages when the beam sections are heavily reinforced, as it would increase both the flexural strength and the ductility of the beam sections.

\section{Variations of neutral axis depth and steel strain with curvature}

To study the changes in flexural behaviour due to the provision of confinement to the beam sections, the variations of the neutral axis depth and steel strain with 
curvature for beam sections with $f_{\mathrm{c}}=70 \mathrm{MPa}$ are shown in Fig. 6. (Those for beam sections with $f_{\mathrm{c}}=$ $30 \mathrm{MPa}$ are similar, and thus are not shown for brevity.)

From Fig. 6(a) it can be seen that, in an underreinforced section, the neutral axis depth at first remains at a constant value when both the concrete and the steel reinforcement are still elastic, and then decreases to a minimum value when the materials become inelastic. However, after entering into the post-peak stage, the neutral axis depth starts to increase. This happens in both the unconfined and confined concrete beam sections. Comparing the variations of the neutral axis depth in the various concrete beam sections with different confining stresses applied, it is evident that the provision of confinement in an under-reinforced section has the effect of slowing down the rate of increase of the neutral axis depth at the post-peak stage. Owing to the gradual increase of the neutral axis depth, the distance between the tension reinforcement and the neutral axis decreases in the post-peak stage, and eventually the strain in the tension reinforcement starts to decrease (strain reversal occurs). As revealed by the plotted steel strain curves, the curvature at which strain reversal occurs and the maximum steel strain reached are dependent on the confining stress applied: at a larger confining stress, the curvature at which strain

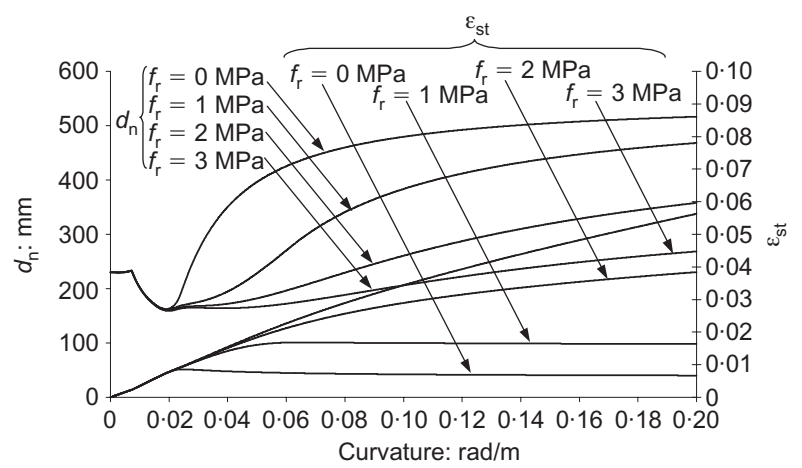

(a)

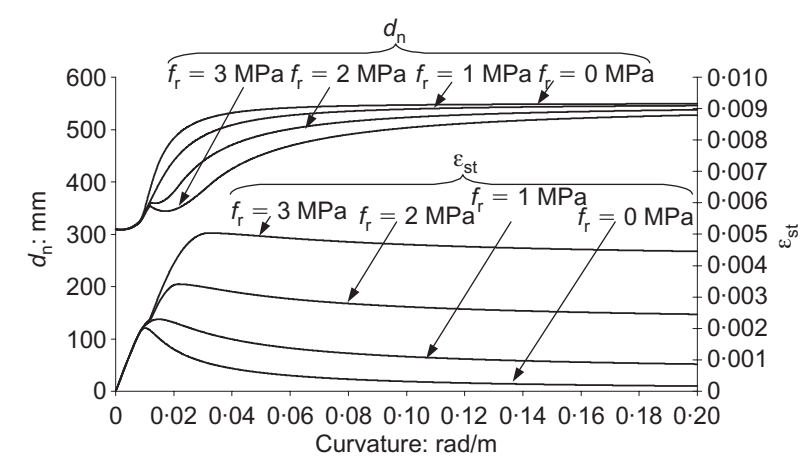

(b)

Fig. 6. Variations of $d_{\mathrm{n}}$ and $\varepsilon_{\mathrm{st}}$ with curvature: (a) underreinforced section $\left(f_{\mathrm{c}}=70 \mathrm{MPa}, \rho_{\mathrm{t}}=0 \cdot 5 \rho_{\mathrm{b}\left(f_{\mathrm{r}}=0 M P a\right)}\right) ;(b)$ over-reinforced section $\left(f_{\mathrm{c}}=70 \mathrm{MPa}, \rho_{\mathrm{t}}=1 \cdot 2 \rho_{\mathrm{b}}\left(f_{\mathrm{r}}=0 M P a\right)\right.$ reversal occurs and the maximum steel strain reached are larger.

On the other hand, it can be seen from Fig. 6(b) that, in an over-reinforced section, the neutral axis depth at first remains at a constant value when both the concrete and the steel reinforcement are still elastic, and then starts to increase when the materials become inelastic. After entering into the post-peak stage, the neutral axis depth continues to increase until it reaches a certain maximum value asymptotically. This happens in all the concrete beam sections. As in the previous case, the provision of confinement in an over-reinforced section has the effect of slowing down the rate of increase of the neutral axis depth in the post-peak stage, and consequently the curvature at which strain reversal occurs and the maximum steel strain reached are significantly larger when the confining stress applied is larger.

\section{Increase in balanced steel ratio due to confinement}

Another significant effect of providing confinement to the beam section is the change in balanced steel ratio of the beam section. The confinement prolongs the stress-strain curve of the concrete, and as a result the ultimate concrete strain when the beam section reaches the peak resisting moment would be increased. Consequently, the balanced steel ratio - that is, the steel ratio at which balanced failure occurs (tension reinforcement just reaching yield stress when the beam section fails) - would increase. In this study, the balanced steel ratio is evaluated by a trial and error process of analysing beam sections with different tension steel ratios and checking whether the tension reinforcement has ever yielded. If the tension reinforcement just yields before strain reversal as the beam section is loaded until complete failure, the beam section is regarded as a balanced section and its tension steel ratio is taken as the balanced steel ratio. The balanced steel ratios, $\rho_{0}$, so obtained for concrete beam sections with different values of $f_{\mathrm{c}}$ and $f_{\mathrm{r}}$ are listed in Table 1 .

From the numerical results, it can be seen that the balanced steel ratio of an unconfined beam section increases with the concrete strength, but that the percentage increase is progressively smaller than the corresponding percentage increase in concrete strength. The balanced steel ratio of a confined beam section also increases with the concrete strength. More importantly,

Table 1. Balanced steel ratio, $\rho_{\mathrm{b}}$, for concrete beam sections with $\mathrm{c}=40 \mathrm{~mm}$

\begin{tabular}{l|c|c|c|c}
\hline \multirow{2}{*}{$f_{\mathrm{c}}: \mathrm{MPa}$} & \multicolumn{4}{|c}{ Value of $\rho_{\mathrm{b}}: \%$} \\
\cline { 2 - 5 } & $f_{\mathrm{r}}=0 \mathrm{MPa}$ & $f_{\mathrm{r}}=1 \mathrm{MPa}$ & $f_{\mathrm{r}}=2 \mathrm{MPa}$ & $f_{\mathrm{r}}=3 \mathrm{MPa}$ \\
\hline 30 & $3 \cdot 18$ & $4 \cdot 19$ & 4.93 & 5.62 \\
50 & $4 \cdot 66$ & $5 \cdot 80$ & 6.63 & $7 \cdot 42$ \\
70 & 6.02 & $7 \cdot 19$ & 8.06 & 8.90 \\
90 & $7 \cdot 24$ & 8.42 & 9.31 & $10 \cdot 16$ \\
\hline
\end{tabular}

Magazine of Concrete Research, 2004, 56, No. 5 
the balanced steel ratio of a confined beam section is dependent on the confining stress applied, being significantly higher when the confining stress is larger.

\section{Flexural ductility}

\section{Flexural ductility evaluation}

The flexural ductility of a beam section may be evaluated in terms of a curvature ductility factor, $\mu$, defined by

$$
\mu=\frac{\phi_{\mathrm{u}}}{\phi_{\mathrm{y}}}
$$

where $\phi_{\mathrm{u}}$ and $\phi_{\mathrm{y}}$ are the ultimate curvature and yield curvature respectively. The ultimate curvature, $\phi_{\mathrm{u}}$, is taken as the curvature of the beam section when the resisting moment of the beam section has, after reaching the peak value of $M_{\mathrm{p}}$, dropped to $0 \cdot 8 M_{\mathrm{p}}$. The yield curvature, $\phi_{\mathrm{y}}$, is taken as the curvature at the hypothetical yield point of an equivalent linearly elasticperfectly plastic system with an elastic stiffness equal to the secant stiffness of the section at $0.75 M_{\mathrm{p}}$ and a yield moment equal to $M_{\mathrm{p}}$.

\section{Ductility of unconfined concrete beam sections}

The values of $\mu$ so evaluated for unconfined concrete beam sections with $f_{\mathrm{c}}=30,50,70$ or $90 \mathrm{MPa}$ are plotted against $\rho_{\mathrm{t}}$ in Fig. 7(a). It can be seen that in general, at a given concrete strength $f_{\mathrm{c}}, \mu$ decreases as $\rho_{\mathrm{t}}$ increases. However, at a given tension steel ratio $\rho_{\mathrm{t}}$,
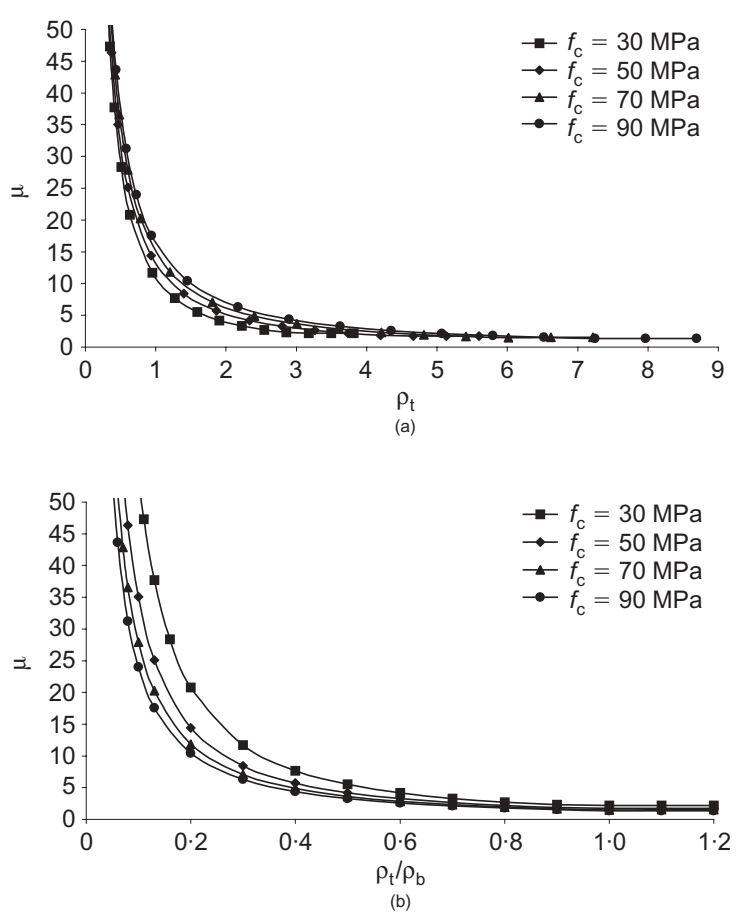

Fig. 7. $\mu$ of unconfined sections $(c=40 \mathrm{~mm})$ : (a) plotted against $\rho_{\mathrm{t}}$; (b) plotted against $\rho_{\mathrm{t}} / \rho_{\mathrm{b}}$ $\mu$ increases slightly with $f_{\mathrm{c}}$. Hence the use of a higher concrete strength could lead to an increase in flexural ductility, although a higher strength concrete is by itself more brittle. This may be explained by the fact that, at a higher concrete strength, the balanced steel ratio is higher, as revealed by Table 1, and thus, for a given tension steel ratio, the tension to balanced steel ratio, $\rho_{\mathrm{t}} / \rho_{\mathrm{b}}$, is lower, leading to a higher degree of the beam section being under-reinforced or a lower degree of the beam section being over-reinforced and eventually to a higher flexural ductility. The increase in flexural ductility due to the reduction in the $\rho_{\mathrm{t}} / \rho_{\mathrm{b}}$ ratio has outweighed the decrease in flexural ductility due to the reduction in ductility of the concrete.

To study how the tension to balanced steel ratio $\rho_{\mathrm{t}} /$ $\rho_{\mathrm{b}}$ affects the flexural ductility, the values of $\mu$ are plotted against $\rho_{\mathrm{t}} / \rho_{\mathrm{b}}$ in Fig. 7(b). It can seen that, at a given concrete strength $f_{\mathrm{c}}, \mu$ decreases as $\rho_{\mathrm{t}} / \rho_{\mathrm{b}}$ increases, and at a given tension to balanced steel ratio $\rho_{\mathrm{t}} / \rho_{\mathrm{b}}, \mu$ decreases slightly as $f_{\mathrm{c}}$ increases, which is more in line with the general conception that a higherstrength concrete is by itself less ductile.

\section{Ductility of confined concrete beam sections}

The values of $\mu$ for confined concrete beam sections with $f_{\mathrm{c}}=30,50,70$ or $90 \mathrm{MPa}$ and $f_{\mathrm{r}}$ ranging from 0 to $3 \mathrm{MPa}$ are plotted against $\rho_{\mathrm{t}}$ in Fig. 8. From the curves plotted, it is evident that, regardless of the concrete strength $f_{\mathrm{c}}$, at a given tension steel ratio, $\rho_{\mathrm{t}}, \mu$ increases significantly with $f_{\mathrm{r}}$. For instance, at a tension steel ratio of $\rho_{\mathrm{t}}=3 \%$, when the confining stress, $f_{\mathrm{r}}$, increases from 0 to $2 \mathrm{MPa}$, the ductility factor, $\mu$, of a beam section with $f_{\mathrm{c}}=30 \mathrm{MPa}$ increases from $2 \cdot 2$ to $9 \cdot 8$, and that of a beam section with $f_{\mathrm{c}}=70 \mathrm{MPa}$ increases from 3.6 to $12 \cdot 0$. This implies that, with the same amount of tension reinforcement added, the provision of confinement could significantly increase the flexural ductility of the beam section, irrespective of whether it is cast in normal or high-strength concrete. Hence the provision of confinement is an effective means of improving the flexural ductility of a beam section without changing the amount of tension reinforcement added to the beam section.

However, it may also be argued that the increase in flexural ductility arising from the provision of confinement is due partly to the increase in balanced steel ratio when confinement is provided, which leads to a significant reduction in the tension to balanced steel ratio, $\rho_{\mathrm{t}} /$ $\rho_{\mathrm{b}}$. To study the net increase in flexural ductility at a fixed tension to balanced steel ratio $\rho_{\mathrm{t}} / \rho_{\mathrm{b}}$, the values of $\mu$ presented in Fig. 8 are re-plotted against $\rho_{\mathrm{t}} / \rho_{\mathrm{b}}$ in Fig. 9. It can be seen from the re-plotted curves that even at a fixed tension to balanced steel ratio, $\rho_{\mathrm{t}} / \rho_{\mathrm{b}}, \mu$ increases significantly with $f_{\mathrm{r}}$. Hence, even at the same degree of the beam section being under/over-reinforced measured in terms of the $\rho_{\mathrm{t}} / \rho_{\mathrm{b}}$ ratio, a beam section provided with a higher confining stress has a higher flexural ductility. The increase in flexural ductility at 


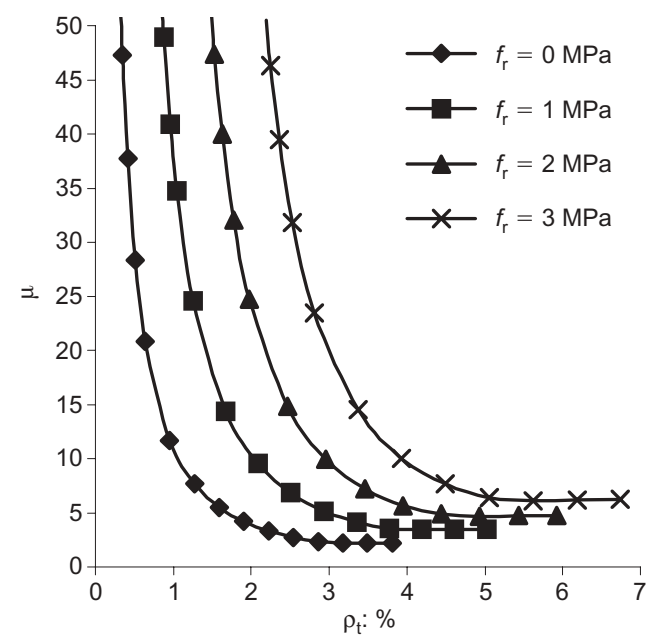

(a)

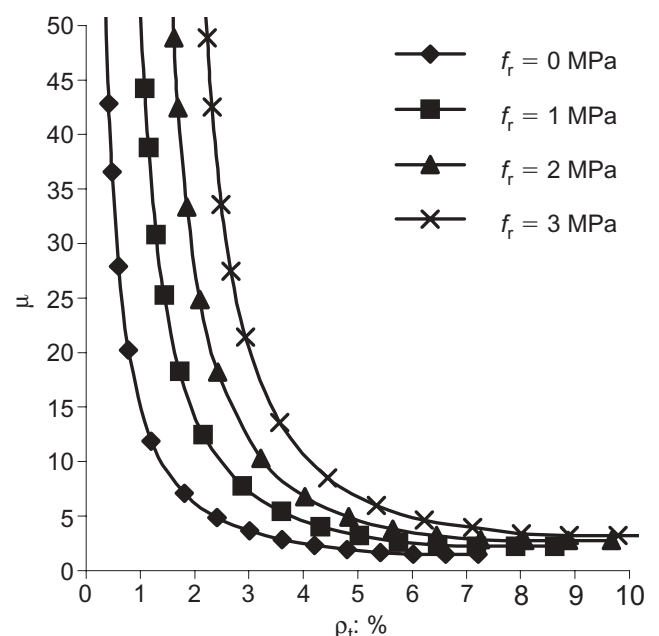

(c)

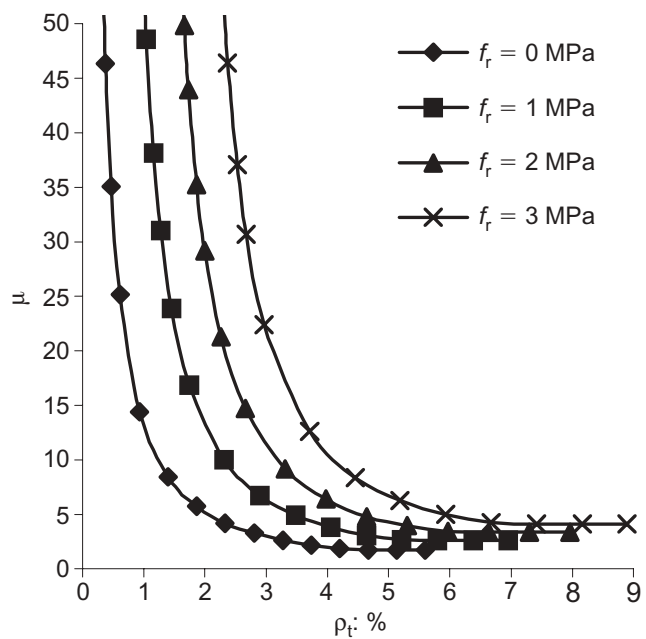

(d)

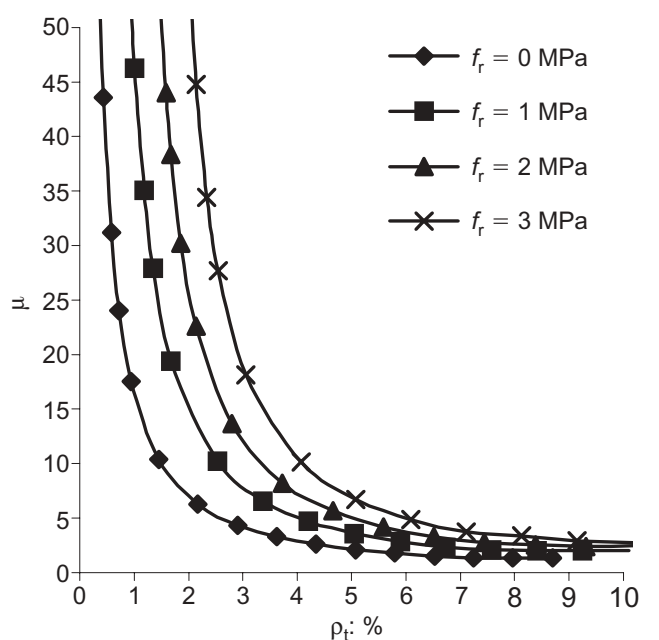

(d)

Fig. 8. $\mu$ of confined sections plotted against $\rho_{\mathrm{t}}(c=40 \mathrm{~mm})$ : (a) $f_{\mathrm{c}}=30 \mathrm{MPa}$; (b) $f_{\mathrm{c}}=50 \mathrm{MPa}$; (c) $f_{\mathrm{c}}=70 \mathrm{MPa}$; (d) $f_{\mathrm{c}}=90 \mathrm{MPa}$

the same $\rho_{\mathrm{t}} / \rho_{\mathrm{b}}$ ratio due to the provision of confinement is attributed to the improved ductility of the concrete rendered by the confinement.

It may be inferred from the above results that the provision of confinement improves the flexural ductility of a beam section in two additive ways. First, it increases the strain at peak stress of the concrete, thereby increasing the ultimate strain of the concrete and the balanced steel ratio of the beam section. As a result, at a given tension steel ratio, the tension to balanced steel ratio of the beam section is reduced and the degree of the beam section being under-reinforced is increased or the degree of the beam section being over-reinforced is decreased. Second, even at the same tension to balanced steel ratio - that is, at the same degree of the beam section being under/over-reinforced-it increases the flexural ductility of the beam section by virtue of the increased residual strength and improved ductility of the concrete rendered by the confinement. Added together, the provision of confinement is particularly effective in improving the flexural ductility of a beam section or in restoring the flexural ductility of a beam section to a more acceptable level, when its flexural ductility has been reduced by the use of high-strength concrete and/or the addition of heavy tension reinforcement.

\section{Effect of partial confinement}

Owing to the finite size of the confining reinforcement and the need to provide a minimum concrete cover, it is not possible to provide confinement to the whole compression zone of the concrete section. There always remains an unconfined zone with a thickness of $c$, as shown in Fig. 3. To study the effect of such partial 


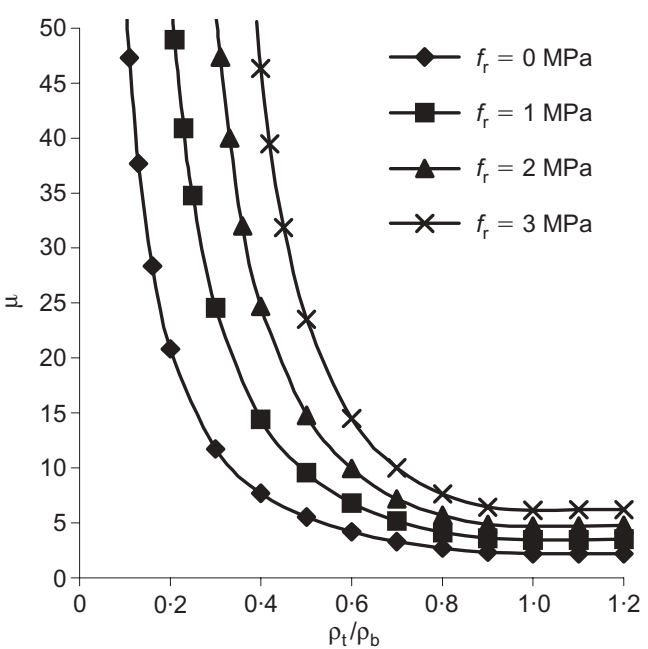

(a)

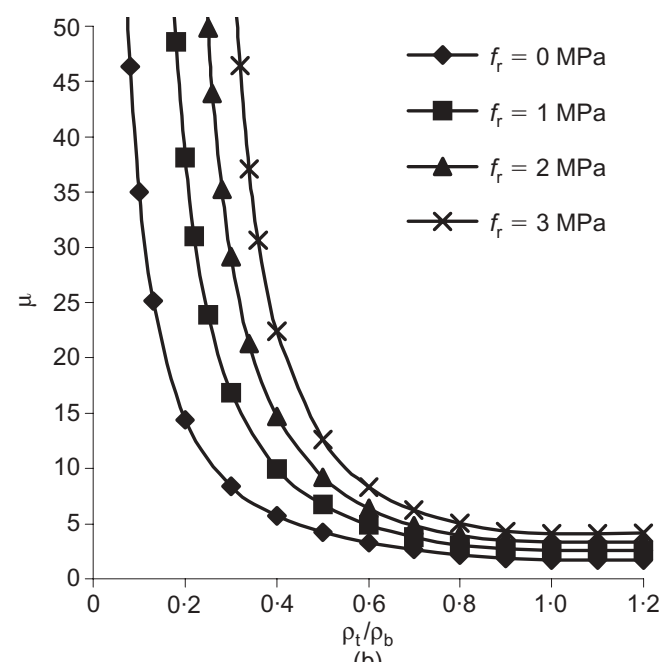

(b)
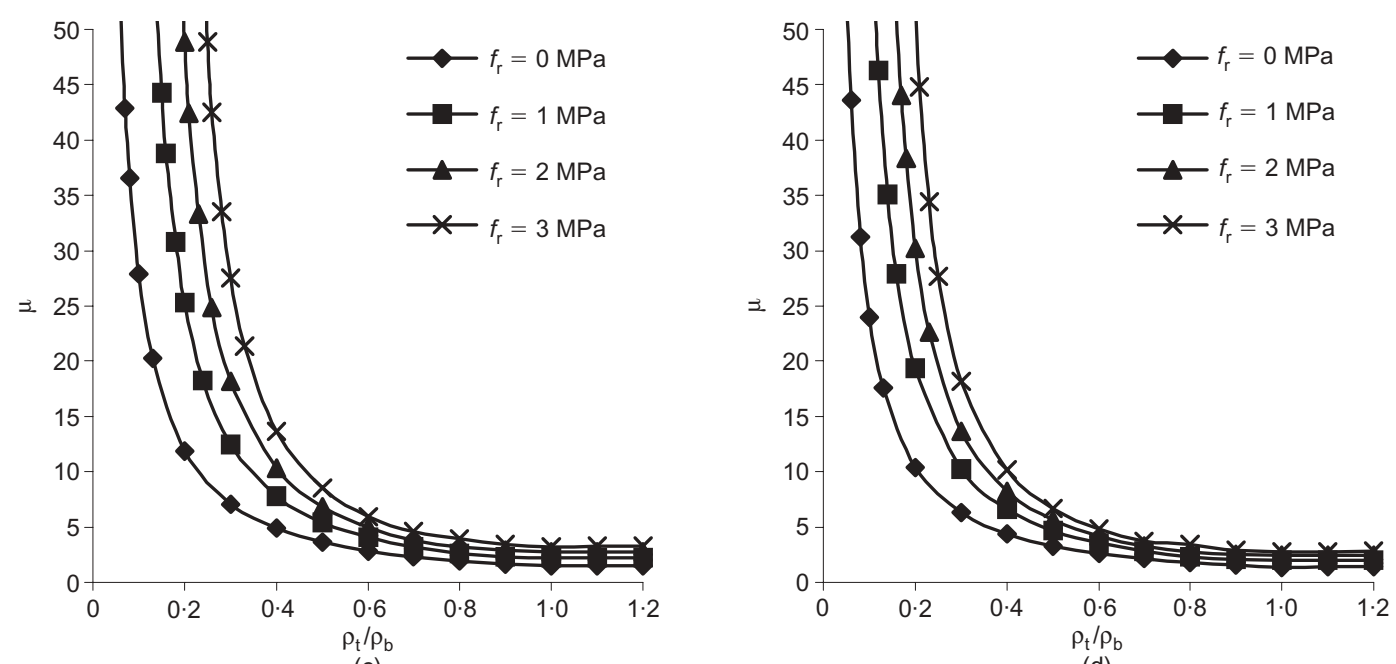

(d)

Fig. 9. $\mu$ of confined sections plotted against $\rho_{\mathrm{t}} / \rho_{\mathrm{b}}(c=40 \mathrm{~mm}):(a) f_{\mathrm{c}}=30 \mathrm{MPa}$; (b) $f_{\mathrm{c}}=50 \mathrm{MPa}$; (c) $f_{\mathrm{c}}=70 \mathrm{MPa}$; (d) $f_{\mathrm{c}}=90 \mathrm{MPa}$

confinement, the thickness of the unconfined zone is varied from 0 to $60 \mathrm{~mm}$ in the parametric study. Fig. 10 shows the effect of such partial confinement in beam sections with $f_{\mathrm{c}}=70 \mathrm{MPa}$. It is evident from the curves plotted that the effect of confinement is dependent on the proportion of the area of the concrete section provided with confinement. The smaller the thickness of the unconfined zone is, or in other words, the larger the area of the confined zone is, the greater would be the effect of the confinement. Hence, when evaluating the effectiveness of providing confinement, the thickness of the unconfined zone needs to be taken into account.

Figures 8 and 9 presented in this paper may be used as design charts for evaluating the effectiveness of providing confinement to improve or restore the flexural ductility of a reinforced concrete beam section. How- ever, when using these figures as design charts, it should be borne in mind that they were derived with the thickness of the unconfined zone, $c$, taken as $40 \mathrm{~mm}$, or as $40 / 300=0 \cdot 13$ of the breadth, $b$, of the section and as $40 / 550=0.07$ of the effective depth, $d$, of the section. These two figures would yield conservative results and are therefore applicable only to confined beam sections with the thickness of the unconfined zone smaller than 0.13 of the breadth and 0.07 of the effective depth.

\section{Conclusions}

The effects of concrete strength and confinement on the complete moment-curvature behaviour of reinforced concrete beam sections have been studied using 


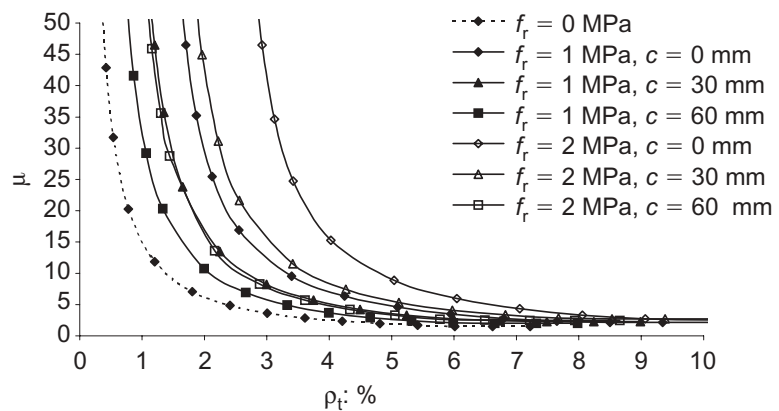

(a)

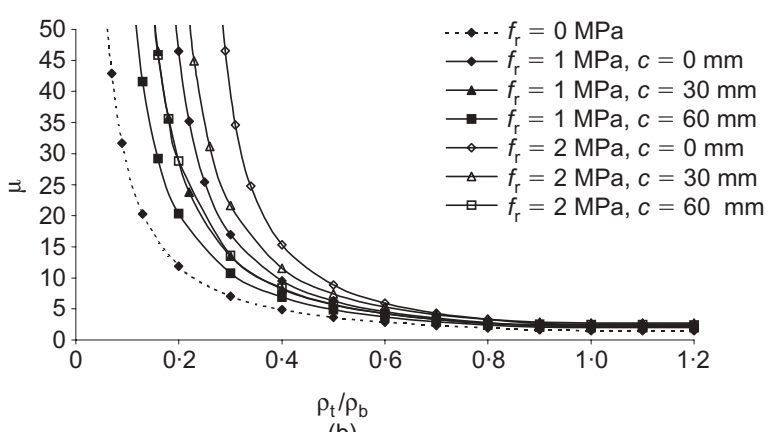

(b)

Fig. 10. $\mu$ of partially confined sections: (a) $f_{\mathrm{c}}=70 \mathrm{MPa}, \mu$ plotted against $\rho_{\mathrm{t}}$; (b) $f_{\mathrm{c}}=70 \mathrm{MPa}, \mu$ plotted against $\rho_{\mathrm{t}} / \rho_{\mathrm{b}}$

a newly developed theoretical method that uses the actual stress-strain curves of the materials and takes into account the stress-path dependence of the stressstrain relation of the tension reinforcement due to strain reversal. Based on the theoretical results obtained, the following conclusions may be drawn.

(a) For under-reinforced sections cast in normal or high-strength concrete, confinement has no effect on the flexural strength but has the beneficial effect of significantly improving the flexural ductility. For over-reinforced sections cast in normal or high-strength concrete, confinement has the effects of slightly increasing the flexural strength and substantially improving the flexural ductility.

(b) In both unconfined and confined sections, at the post-peak stage, the neutral axis depth would keep on increasing, leading to gradual reduction of the distance between the tension reinforcement and the neutral axis, and eventually to strain reversal in the tension reinforcement. In general, the provision of confinement has the effect of slowing down the rate of increase of the neutral axis depth and increasing the maximum strain reached by the tension reinforcement. The provision of confinement also has the effect of increasing the balanced steel ratio.

(c) Regardless of the concrete strength, at a given tension steel ratio the flexural ductility of a beam section increases substantially with the confining stress applied. Even at a given tension to balanced steel ratio, the flexural ductility of a beam section increases significantly with the confining stress applied. Hence the provision of confinement is an effective means of improving or restoring the flexural ductility of a beam section, irrespective of whether it is cast of normal or high-strength concrete.

(d) The effectiveness of the confinement provided is dependent on the proportion of the area of the concrete section provided with confinement. The smaller the thickness of the unconfined zone, or in other words the larger the area of the confined zone, the greater would be the effect of the confinement.

(e) The two figures showing how the flexural ductility varies with the confining stress (Figs 8 and 9) may be used as design charts for evaluating the effectiveness of providing confinement to improve or restore the flexural ductility of any beam section with the thickness of the unconfined zone inside the beam section smaller than $0 \cdot 13$ of the breadth and 0.07 of the effective depth.

\section{Appendix: Evaluation of confining stress}

The confining stress, $f_{\mathrm{r}}$, may be evaluated using the method proposed by Mander et al., ${ }^{15}$ as outlined below. For convenience, it is assumed that the area of the confined concrete is the area of concrete bounded by the transverse reinforcement (denoted herein by $A_{\mathrm{cc}}$ ). However, owing to the arching action of the lateral confining pressure, not all the concrete area bounded by the transverse reinforcement is effectively confined. In a rectangular concrete section, arching occurs longitudinally between adjacent layers of transverse reinforcement and transversely between adjacent longitudinal reinforcing bars. As a result, the effectively confined concrete area (denoted herein by $A_{\mathrm{e}}$ ) is smaller than the concrete area bounded by the transverse reinforcement. Mander et al. suggested that $A_{\mathrm{e}}$ may be determined from $A_{\mathrm{cc}}$ by subtracting the parabolas (each assumed to have an initial slope of $45^{\circ}$ ) containing the ineffectively confined concrete, and that to allow for the difference between $A_{\mathrm{e}}$ and $A_{\mathrm{cc}}$, the confining stress should be reduced by a factor $K_{\mathrm{e}}$, defined as $K_{\mathrm{e}}=A_{\mathrm{e}} / A_{\text {cc }}$. Hence the effective confining stress, $f_{\mathrm{r}}$, is given by

$$
f_{\mathrm{r}}=K_{\mathrm{e}} f_{\mathrm{p}}
$$

in which $f_{\mathrm{p}}$ is the lateral confining pressure provided by the transverse reinforcement. In the case of a rectangular section, the confining pressure is generally different in the $x$ and $y$ directions (the two orthogonal directions in the section), but nevertheless the confining pressure for use in equation (10) may be taken as a weighted average of the confining pressure in the $x$ and $y$ direc- 
tions, and may be evaluated using the following formula $^{16}$

$$
f_{\mathrm{p}}=\frac{f_{\mathrm{yh}}}{s}\left(\frac{A_{\mathrm{s} x}+A_{\mathrm{s} y}}{b_{\mathrm{c}}+d_{\mathrm{c}}}\right)
$$

where $f_{\mathrm{yh}}$ is the yield strength of the transverse reinforcement, $s$ is the spacing of the transverse reinforcement, $A_{\mathrm{s} x}$ and $A_{\mathrm{s} y}$ are the total area of transverse reinforcement in the $x$ and $y$ directions, and $b_{\mathrm{c}}$ and $d_{\mathrm{c}}$ are the breadth and depth of the concrete core respectively.

\section{References}

1. ACI Committee 363. State-of-the-Art Report on High Strength Concrete. American Concrete Institute, Detroit, 1992, ACI 363R92.

2. Carreira D. J. and ChU K. H. The moment-curvature relationship of reinforced concrete members. ACI Journal, 1986, 83, No. 2, 191-198.

3. Sheikh S. A. and YeH C. C. Analytical moment-curvature relations for tied concrete columns. Journal of Structural Engineering, ASCE, 1992, 118, No. 2, 529-544.

4. Samra R. M., Deeb N. A. A. and Madi U. R. Transverse steel content in spiral concrete columns subjected to eccentric loading. ACI Structural Journal, 1996, 93, No. 4, 412-419.

5. Pam H. J., Kwan, A. K. H. and Ho J. C. M. Post-peak behavior and flexural ductility of doubly reinforced normal- and highstrength concrete beams. Structural Engineering and Mechanics, 2001, 12, No. 5, 459-474.

6. Ho J. C. M., Kwan A. K. H. and PAM H. J. Ultimate concrete strain and equivalent rectangular stress block for design of highstrength concrete beams. Structural Engineer, 2002, 80, No. 16, 26-32.
7. Kwan A. K. H., Ho J. C. M. and Pam H. J. Effects of concrete grade and steel yield strength on flexural ductility of reinforced concrete beams. Australian Journal of Structural Engineering (to be published).

8. Рам H. J., Kwan A. K. H. and Islam M. S. Flexural strength and ductility of reinforced normal- and high-strength concrete beams. Proceedings of the Institution of Civil Engineers-Structures and Buildings, 2001, 146, No. 4, 381-389.

9. Sheikh S. A., Shah D. V. and Khoury S. S. Confinement of high-strength concrete columns. ACI Structural Journal, 1994, 91, No. 1, 100-111.

10. Cusson D. and Paultre P. High-strength concrete columns confined by rectangular ties. Journal of Structural Engineering, ASCE, 1994, 120, No. 3, 783-804.

11. SaAtcioglu M. and Razvi S. R. High-strength concrete columns with square sections under concentric compression. Journal of Structural Engineering, ASCE, 1998, 124, No. 12, $1438-$ 1447.

12. Attard M. M. and Setunge S. The stress strain relationship of confined and unconfined concrete. ACI Materials Journal, 1996, 93, No. 5, 432-444.

13. Attard M. M. and Stewart M. G. A two parameter stress block for high-strength concrete. ACI Structural Journal, 1998, 95, No. 3, 305-317.

14. PARK R. and Paulay T. Reinforced Concrete Structures. John Wiley \& Sons, New York, 1975.

15. Mander J. M., Priestley N. and Park R. Theoretical stressstrain model for confined concrete. Journal of Structural Engineering, ASCE, 1988, 114, No. 8, 1804-1826.

16. Cusson D. and Paultre P. Stress-strain model for confined high-strength concrete. Journal of Structural Engineering, ASCE, 1995, 121, No. 3, 468-477.

Discussion contributions on this paper should reach the editor by 1 January 2005 